\title{
Evidenciação de emissões ambientais em empresas brasileiras
}

\author{
Disclosure environmental emissions in brazilian companies
}

\begin{abstract}
Mara Vogt', Larissa Degenhart', Caroline Sulzbach Pletsch², Alini da Silva', Fabricia Silva da Rosa ${ }^{3}$
\end{abstract}

\begin{abstract}
RESUMO
Este estudo objetivou analisar como ocorre a evidenciação de emissões ambientais em empresas brasileiras. Dessa forma realizou-se uma pesquisa descritiva, documental e com abordagem qualitativa. A população do estudo foi composta por 100 empresas brasileiras listadas no IBrX100 da BM\&FBovespa ea amostra compreendeu 31 empresas no ano de 2010, 33 em 2011 e 43 em 2012. Analisou-se o conteúdo referente às emissões ambientais dos Relatórios de Sustentabilidade e, ainda, foi realizado um ranking do nível de evidenciação de emissões ambientais das empresas analisadas. Os resultados demonstraram que a maioria das empresas brasileiras não possui Relatórios de Sustentabilidade disponíveis, sendo que àquelas que possuíam os relatórios disponíveis, no que tange às emissões, a maioria divulga dados na forma descritiva e quantitativa. Em relação aos rankings, a empresa P. Açúcar foi a que mais se destacou, pois se preocupa com o meio ambiente e divulga informações sobre as emissões ambientais. A maioria das empresas evidencia informações sobre as emissões destruidoras da Camada de Ozônio e emissões de Nox e Sox. Por fim, a maioria das empresas brasileiras não divulgam dados sobre a redução dessas emissões.
\end{abstract}

Palavras-chave: evidenciação ambiental; emissões; empresas brasileiras.

\begin{abstract}
This study aimed to analyze how the disclosure of environmental issues in Brazilian companies occurs. Thus we carried out a descriptive, documentary approach and qualitative research. The study population was composed of 100 Brazilian companies listed in IBrX100 BM\&FBovespa and the sample included 31 companies in 2010, 33 in 2011 and 43 in 2012 analyzed the content relating to environmental issues Sustainability Reporting and yet, a ranking of the level of disclosure of environmental emissions of the analyzed companies was conducted. The results showed that the majority of Brazilian companies has no sustainability reports available, and those that had the reports available with respect to emissions, most releases data on descriptive and quantitative way. Regarding the rankings, the company P. Açúcar was the one that stood out because it cares about the environment and disseminates information on environmental emissions. Most companies shows information about the destructive emissions of the ozone layer and emission of Nox and Sox. Finally, most Brazilian companies do not disclose data on the reduction of these emissions.
\end{abstract}

Keywords: environmental disclosure; emissions; brazilian companies

\section{INTRODUÇÃO}

Nos últimos anos, de acordo com Jenkins e Yakovleva (2006), a preocupação voltada para a responsabilidade social das empresas e sua sustentabilidade vem sendo discutida em diversos países e, sobretudo, nas indústrias. Além disso, diversas empresas estão reconhecendo a importância das questões ambientais e sociais, isto é, cada vez mais, utilizam os relatórios de sustentabilidade, bem como relatórios anuais para divulgar a sua relação com o meio ambiente para a sociedade (DAUB, 2007).

As empresas mudaram de comportamento para que os relatórios empresariais passassem a apresentar cada vez mais informações sociais e ambientais. Dentre as informações socioambientais divulgadas pelas empresas, destacam-se o comprometimento quanto às diretrizes ambientais, ao impacto e à adaptação de suas atividades no meio ambiente, medidas a serem adotadas para diminuir os efeitos negativos, gastos relacionados à sociedade e meio ambiente, dentre outras informações (RIBEIRO, 2006).

Nesse sentido, as organizações descrevem e divulgam seu desempenho ambiental, relativos a eventos e impactos das atividades empresariais, nos relatórios ambientais, socioambientais, anuais ou suplementos ambientais, permitindo que os usuários compreendam o posicionamento da empresa (TINOCO \& KRAEMER, 2011).

Desta forma, as organizações não devem ignorar a gestão ambiental, cumprindo com os requisitos constitucionais e divulgando suas

$\square$

'Doutorandas em Ciências Contábeis e Administração pela Universidade Regional de Blumenau (FURB) - Blumenau (SC), Brasil.

${ }^{2}$ Mestre em Ciências Contábeis pela FURB - Blumenau (SC), Brasil.

${ }^{3}$ Pós-doutorado em Contabilidade pela Universidade Federal de Santa Catarina (UFSC); Professora da UFSC - Florianópolis (SC), Brasil.

Endereço para correspondência: Mara Vogt - Rua São Paulo, 1196 - Victor Konder - 89012-001 - Blumenau (SC), Brasil - E-mail: maravogtcco@gmail.com

Recebido: 24/09/14 - Aceito: 31/01/16 - Reg. ABES: 140991 
atividades, a fim de se ter transparência dos impactos ao meio ambiente e a sociedade, e, mais do que isso, devem se preocupar com a preservação ambiental (TRIERWEILLER et al., 2012).

Estudos como os de Nossa (2002), Ben (2005), Calixto (2007), Borges, Rosa e Ensslin (2010), Oliveira, Machado e Beuren (2012) e Silva et al. (2013) analisaram a evidenciação ambiental; porém, nenhum analisou especificamente a questão das emissões ambientais.

Diante do exposto, este estudo buscou responder a seguinte questão problema que norteia o desenvolvimento deste estudo: como ocorre a evidenciação de emissões ambientais em empresas brasileiras? Neste sentido, o objetivo desta pesquisa foi o de analisar como ocorre a evidenciação de emissões ambientais em empresas brasileiras.

O estudo justifica-se, visto que os demais analisaram aspectos gerais de evidenciação ambiental e não especificamente as emissões ambientais em companhias brasileiras. Como as emissões referem-se a aspectos negativos sobre a empresa, busca-se evidenciar essas informações ambientais apresentadas nos Relatórios de Sustentabilidade, pois é de interesse da sociedade, a qual se preocupa com o impacto das atividades empresarias no meio ambiente (CARNEIRO; LUCA; OLIVEIRA, 2008; FARIAS \& ANDRADE, 2013).

\section{REFERENCIAL TEÓRICO}

No atual contexto mercadológico, as entidades começam a entender como os usuários e partes interessadas gostariam que fossem a medição, a gestão e a evidenciação dos impactos das atividades empresariais na sociedade e meio ambiente. Para garantir o sucesso financeiro das empresas, é necessário que ampliem os interesses sociais e ambientais, da mesma forma que gerenciam os comerciais. Assim, ao servir aos interesses dos acionistas, da sociedade e do meio ambiente, com prestação de contas e transparência das suas atividades, detêm importante estratégia de crescimento do negócio (LUNGU; CARAIANI; DASCALU, 2007).

Conforme comentam Skouloudis, Evangelinos e Kourmousis (2010), as empresas de todo o mundo estão elaborando outros relatórios além dos de cunho financeiro, com o intuito de cumprir com a prestação de contas, apesar do nível de evidenciação variar de um país para outro. Assim, de acordo com Liu e Anbumozh (2009), a avaliação da evidenciação ambiental é realizada com o objetivo de analisar o que leva as empresas a divulgarem aspectos ambientais, verificando, dessa forma, se as informações disponibilizadas são de qualidade.

As empresas utilizam a evidenciação ambiental para prestar contas à sociedade, diminuindo a assimetria informacional entre a entidade $\mathrm{e}$ seus usuários, como fornecedores, clientes, investidores, governo (ROSA et al., 2011). Divulgam informações referentes aos riscos, impactos, políticas, estratégias, alvos, custos, despesas, receitas, passivos ou demais informações importantes sobre o desempenho ambiental (TINOCO \& KRAEMER, 2011).
Muitas organizações utilizam o Relatório de Sustentabilidade como ferramenta de prestação de contas e estratégia do negócio por abranger aspectos sociais, ambientais e econômicos das atividades. As organizações integram, em suas estratégias, ferramentas de sustentabilidade com o intuito de crescimento e rentabilidade. $\mathrm{O}$ impacto das atividades empresariais sobre a sociedade e o meio ambiente torna-se importante responsabilidade e fonte de estratégia para os gestores organizacionais (LUNGU; CARAIANI; DASCALU, 2007).

Os impactos ambientais, como aquecimento global e poluição dos recursos naturais, ocorrem devido à produção das empresas e alto padrões de consumo de recursos. A prestação de contas e transparência dos impactos das atividades empresariais na sociedade e meio ambiente é relevante por evidenciar informações, entretanto, não é suficiente como tentativa de diminuir a poluição. As informações socioambientais divulgadas são importantes ao mercado e ao Governo, por evidenciarem o impacto das atividades empresariais, que influenciam a tomada de decisões de usuários quanto ao relacionamento com a empresa (ERLANDSON \& TILLMAN, 2009).

De acordo com Ferreira (2011), o objetivo da gestão ambiental nas empresas é o de propiciar benefícios que superam os custos de degradação ambiental, causada principalmente pela área produtiva. A degradação ambiental é ocasionada por ações que geram danos e poluição, que, por sua vez, impactam na sociedade, meio ambiente e também no patrimônio da entidade. Desta forma, a gestão ambiental nas organizações atua para que este impacto se torne positivo e minimize os prejuízos. Ainda, para que a gestão ambiental das empresas atue na diminuição dos impactos, deve identificar os tipos de emissão de resíduos sólidos, líquidos e gasosos.

Diversas são as pesquisas sobre a gestão ambiental e evidenciação dos impactos ao meio ambiente, contribuindo com a importância da transparência empresarial perante aos usuários (CALIXTO, 2007). Diante disso, discussões políticas ganharam robustez ao longo dos anos, sobre os efeitos no meio ambiente, desenvolvendo desta forma, eventos, tratados, grupos como o Intergovernmental Panel on Climate Change (IPCC) em 1988, United Nations Framework Convention on Climate Change (UNFCCC), colaborada no Brasil pela Conferência Internacional sobre Meio Ambiente e Desenvolvimento (Eco 92) em 1992, Conference of the Parties 1 (COP - 1) em 1995 até a COP 13 em 2007, Protocolo de Kyoto em 1997, Declaração de Genebra em 1996, Pacto Global em 1999, criação do Fórum Brasileiro de Mudanças Climáticas em 2000 e a Cúpula Mundial de Desenvolvimento Sustentável (Rio+10) em 2002. Eventos como estes que discutem e cobram soluções, sobre a postura social frente aos problemas ambientais (FARIAS, 2008).

As emissões ambientais já foram objeto de estudo de diferentes ambientes e abordadas por diversos autores em todo o mundo. O estudo de Nossa (2002) investigou o nível de disclosure de informações ambientais apresentado por empresas do setor de papel e celulose em seus relatórios ambientais. Constatou que o nível de evidenciação 
ambiental diverge em relação ao tamanho da empresa, país e tipo de relatório analisado. Além disso, verificaram que a maioria das informações ambientais é evidenciada de forma descritiva. Ben (2005) analisou a divulgação de aspectos inerentes às informações ambientais nas demonstrações contábeis de empresas do Rio Grande do Sul. Os resultados demonstram a ausência de divulgação de informações ambientais nas demonstrações contábeis das empresas analisadas.

O estudo de Calixto (2007) examinou nas companhias de capital aberto de 17 setores no Brasil através de informações ambientais divulgadas nos relatórios contábeis. Constatou que há um crescimento contínuo de informações ambientais divulgadas nos relatórios contábeis. Ainda, verificou diferença no nível de evidenciação entre setores e empresas, em que algumas empresas divulgaram mais informações do que outras.

Borges, Rosa e Ensslin (2010) investigaram a evidenciação voluntária das práticas ambientais nas vinte maiores empresas brasileiras de papel e celulose. Os resultados encontrados demonstraram que os itens mais evidenciados foram: "Reserva natural", "Monitoramento para evitar impactos ambientais", "Redução de emissões atmosféricas" e "Projetos focados na educação ambiental junto à comunidade e colaboradores". Verificaram, também, que a empresa Votorantim foi a que mais divulgou práticas ambientais nos relatórios investigados.

Oliveira, Machado e Beuren (2012) desenvolveram um estudo para identificar nas empresas potencialmente poluidoras listadas no Índice de Sustentabilidade Empresarial (ISE) o nível de evidenciação ambiental divulgado voluntariamente. Os resultados demonstraram que a categoria mais evidenciada foi a Política Ambiental e as menos evidenciadas foram as categorias de Energia e Impactos dos Processos no Meio Ambiente. Quanto ao ranking de evidenciação, a Suzano Papel foi a que se destacou.

Já no estudo de Silva et al. (2013), os autores identificaram em companhias listadas na BM\&FBOVESPA pertencentes a segmentos potencialmente poluidores as características da evidenciação ambiental sobre resíduos sólidos. A partir da análise dos relatórios, constataram que, dentre os 10 itens analisados, seis estão sendo evidenciados em nível de excelência por no mínimo 10 empresas - o que indica que as pertencentes a segmentos potencialmente poluidores têm a tendência de divulgar informações ambientais de forma voluntária.

\section{PROCEDIMENTOS METODOLÓGICOS}

Para analisar a evidenciação ambiental sobre as emissões das empresas brasileiras, realizou-se uma pesquisa descritiva, documental e qualitativa. A população do estudo é composta por 100 empresas brasileiras listadas no IBrX100 da BM\&FBovespa e a amostra constitui-se de 31 empresas em 2010, 33 em 2011 e 43 em 2012, visto que estas demais empresas não divulgaram em seus Relatórios de Sustentabilidade, dados sobre as emissões ambientais.

Os Relatórios de Sustentabilidade foram coletados no sítio das empresas brasileiras analisadas, sendo que as demais não apresentaram este relatório. O período de análise foi de 2010 a 2012 e foi analisado o conteúdo referente às emissões ambientais dos Relatórios de Sustentabilidade divulgados por estas empresas. No Quadro 1, apresentam-se os clusters, os fatores sobre emissões e os aspectos analisados nos Relatórios de Sustentabilidade das empresas brasileiras.

Quadro 1 - Principais características da evidenciação ambiental sobre emissões.

\begin{tabular}{|c|c|}
\hline Cluster & $\begin{array}{l}\text { Aspectos analisados nos } \\
\text { Relatórios de Sustentabilidade }\end{array}$ \\
\hline \multicolumn{2}{|l|}{ 1. Emissões diretas } \\
\hline 1.1 Tipo de Informação & $\begin{array}{l}\text { Tipo de informação: Descritiva, } \\
\text { Monetária, Quantitativa e/ou ambos }\end{array}$ \\
\hline 1.2 Gestão de desempenho & $\begin{array}{l}\text { Divulga como os níveis de } \\
\text { responsabilidade ambiental estão } \\
\text { divididas na empresa: Alta Direção, } \\
\text { Diretores e corpo Operativo. }\end{array}$ \\
\hline 1.2.1 Sistema métrico & $\begin{array}{l}\text { Utiliza Sistema Métrico Internal (SMI) e/ } \\
\text { ou Padrão de Conversão (PC). }\end{array}$ \\
\hline 1.2.2 Uso de protocolos & $\begin{array}{l}\text { Utiliza protocolos para informações } \\
\text { prestadas. }\end{array}$ \\
\hline 1.2.3 Tendências & $\begin{array}{l}\text { Periodicidade informada dos } \\
\text { programas. }\end{array}$ \\
\hline \multicolumn{2}{|l|}{ 2. Emissões indiretas } \\
\hline 2.1 Tipo de Informação & $\begin{array}{l}\text { Tipo de informação: Descritiva, } \\
\text { Monetária, Quantitativa e/ou ambos. }\end{array}$ \\
\hline 2.2 Gestão de desempenho & $\begin{array}{l}\text { Divulga como os níveis de } \\
\text { responsabilidade ambiental estão } \\
\text { divididas na empresa: Alta Direção, } \\
\text { Diretores e corpo Operativo. }\end{array}$ \\
\hline 2.2.1 Sistema métrico & $\begin{array}{l}\text { Utiliza Sistema Métrico Internal (SMI) e/ } \\
\text { ou Padrão de Conversão (PC). }\end{array}$ \\
\hline 2.2.2 Uso de protocolos & $\begin{array}{l}\text { Utiliza protocolos para informações } \\
\text { prestadas. }\end{array}$ \\
\hline 2.2.3 Tendências & $\begin{array}{c}\text { Periodicidade informada dos } \\
\text { programas. }\end{array}$ \\
\hline $\begin{array}{l}\text { 3. Emissões de substâncias } \\
\text { destruidoras da Camada } \\
\text { de Ozônio }\end{array}$ & $\begin{array}{c}\text { Apresentam informações sobre as } \\
\text { emissões de substâncias destruidoras } \\
\text { da Camada de Ozônio. }\end{array}$ \\
\hline $\begin{array}{l}\text { 4. Emissões de Nox, Sox, e } \\
\text { outras substâncias significativas }\end{array}$ & $\begin{array}{c}\text { Apresentam informações sobre as } \\
\text { emissões de substâncias destruidoras } \\
\text { da Camada de Ozônio. }\end{array}$ \\
\hline \multicolumn{2}{|l|}{ 5. Redução de Emissões } \\
\hline 5.1 Tipo de Informação & $\begin{array}{l}\text { Tipo de informação: Descritiva, } \\
\text { Monetária, Quantitativa e/ou ambos. }\end{array}$ \\
\hline 5.2 Ocorrência & $\begin{array}{c}\text { Identifica as iniciativas de redução e } \\
\text { as respectivas áreas da empresa onde } \\
\text { ocorrem. }\end{array}$ \\
\hline 5.3 Tendências & $\begin{array}{l}\text { Periodicidade informada dos } \\
\text { programas. }\end{array}$ \\
\hline
\end{tabular}


Os dados foram tabulados a partir do programa do Excel, ou seja, planilhas eletrônicas ou folhas de cálculo que possibilitam realizar cálculos matemáticos. A análise foi realizada por meio de um ranking, sendo que em alguns casos utilizou-se do ranking geral sobre emissões e, para algumas análises, optou-se pelo ranking de algum grupo dos fatores expostos no Quadro 1. A análise apresenta-se em forma de quadros, tabelas e figuras para melhor entendimento do assunto.

\section{ANÁLISE DOS DADOS}

Por meio da análise dos dados divulgados nos Relatórios de Sustentabilidade, analisou-se o nível de evidenciação ambiental referente às emissões das empresas brasileiras. A análise divide-se em emissões, na qual foi apresentado um panorama geral dos fatores que foram analisados, seguido de um ranking geral dos três anos, considerando as dez empresas que lideraram em relação a amostra anual da pesquisa. Na sequência, foram abordadas as emissões diretas, as emissões indiretas, uma análise descritiva sobre as emissões de substâncias destruidoras da Camada de Ozônio e as emissões de Nox, Sox e outras substâncias significativas. Por fim, por meio de um ranking, apresentou-se as empresas que mais divulgam informações referentes a redução de emissões.

\section{Emissões}

Nesta seção, apresentam-se as emissões ambientais que foram verificadas a partir dos Relatórios de Sustentabilidade das empresas brasileiras listadas na BM\&FBovespa. Inicialmente, aborda-se sobre as emissões ambientais no geral, por meio de um ranking das dez empresas brasileiras que apresentaram maior evidenciação dos fatores analisados. Na Figura 1, observa-se a divisão das emissões ambientais.

De acordo com o que pode ser conferido na Figura 1, nota-se que as emissões dividem-se em: emissões diretas, emissões indiretas, emissões de substâncias destruidoras da Camada de Ozônio, emissões de Sox,
Nox e outras e, ainda, a redução de emissões. Tanto as emissões diretas quanto as indiretas apresentam a divisão emtre tipo de informação e gestão de desempenho - visto que a última possui mais três divisões, sendo o sistema métrico, uso de protocolos e tendências. Além disso, a redução de emissões divide-se em tipo de informação, ocorrência e tendências. Na sequência, a partir do Quadro 2, apresenta-se o ranking das empresas brasileiras que mais evidenciaram sobre emissões em seus Relatórios de Sustentabilidade no período de 2010 a 2012.

Por meio do Quadro 2, percebe-se que a empresa P. Açúcar ficou em $1^{\circ}$ lugar no ranking nos anos de 2011 e 2012, demonstrando a sua preocupação para com o meio ambiente, evidenciando, em seus Relatórios de Sustentabilidade, nestes dois anos, um maior número de aspectos que foram analisados neste estudo, conforme pode ser visto na Figura 1. Verifica-se também que a empresa Klabin S/A apresenta uma boa colocação no ranking, visto que, em 2010, ficou como $3^{\mathrm{a}}$ colocada e, em 2011, como $2^{\mathrm{a}}$; porém, no ano de 2012, apresentou menos aspectos sobre emissões em seu relatório, não ficando entre as 10 empresas destacadas neste ranking. A empresa

Quadro 2 - Ranking das empresas brasileiras que mais evidenciaram sobre emissões.

\begin{tabular}{|r|c|r|c|r|c|}
\hline & Ranking 2010 & & Ranking 2011 & & Ranking 2012 \\
\hline $1^{a}$ & AMBEV & $1^{a}$ & P. AÇUCAR & $1^{a}$ & P. AÇUCAR \\
\hline $2^{a}$ & ECORODOVIAS & $2^{a}$ & KLABIN S/A & $2^{a}$ & ENERGIAS BR \\
\hline $3^{a}$ & KLABIN S/A & $3^{a}$ & BRF FOODS & $3^{a}$ & VALE \\
\hline $4^{a}$ & BRASKEM & $4^{a}$ & DURATEX & $4^{a}$ & TRACTEBEL \\
\hline $5^{a}$ & PETROBRAS & $5^{a}$ & PETROBRAS & $5^{a}$ & SUZANO PAPEL \\
\hline $6^{a}$ & TRACTEBEL & $6^{a}$ & ELETROBRAS & $6^{a}$ & ELETROBRAS \\
\hline $7^{a}$ & DURATEX & $7^{a}$ & TRACTEBEL & $7^{a}$ & DURATEX \\
\hline $8^{a}$ & BRADESCO & $8^{a}$ & BRADESCO & $8^{a}$ & PETROBRAS \\
\hline $9^{a}$ & BRF FOODS & $9^{a}$ & BRASKEM & $9^{a}$ & BRF FOODS \\
\hline $10^{a}$ & LIGHT S/A & $10^{a}$ & EVEN & $10^{a}$ & BRASKEM \\
\hline
\end{tabular}

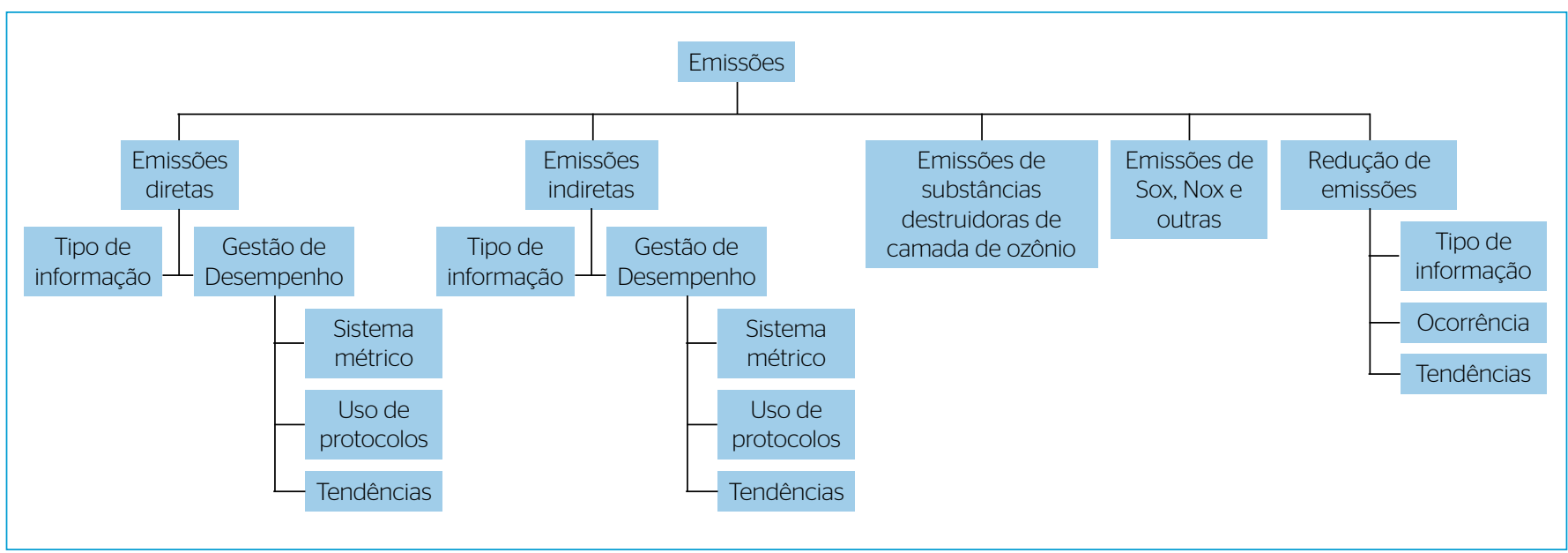

Figura 1 - Emissões ambientais. 
BRF Foods no ano de 2011 apresentou-se em $3^{\circ}$ lugar no ranking, diferente de 2010 e 2012, quando encontrava-se na nona posição em ambos os anos. A empresa Braskem, no ano de 2010, estava com uma melhor colocação no ranking, ou seja, em $4^{\circ}$ posição, diferente de 2011 e 2012 no qual apresentou um declínio frente a evidenciação ambiental sobre emissões.

Além disso, por meio do Quadro 2, nota-se que a empresa Tractebel ficou nos anos de 2010, 2011 e 2012 em 6우 $7^{\circ}$ e $4^{\circ}$ lugar, respectivamente; isto é, no ano de 2012 a empresa passou a evidenciar mais aspectos relacionados as emissões ambientais. Já a empresa Duratex estava na $7^{a}$ posição do ranking em 2010, melhorou em 2011 (ficando com a 4a colocação) e, em 2012, novamente decaiu para a mesma posição do ano de 2010.

No que tange a evidenciação ambiental da empresa Petrobras sobre emissões, verifica-se que em 2010 e 2011 esta empresa ficou na mesma posição no ranking das empresas brasileiras, ou seja, na $5^{\text {a }}$ colocação, sendo que em 2012 caiu para a $8^{\mathrm{a}}$ posição, demonstrando que, neste último ano, deixou de evidenciar alguns aspectos ambientais. Já a empresa Eletrobrás ficou com a 6a colocação em 2011 e 2012; e o Bradesco na 8a posição em 2010 e 2011, sendo que em 2012 decaiu, não estando presente no ranking das dez empresas que mais evidenciam os aspectos sobre emissões na análise. As demais empresas do ranking apenas se encontram, em um dos anos analisados, dentre as dez primeiras posicionadas no ranking geral sobre emissões ambientais.

\section{Emissões diretas}

Nesta seção apresenta-se a primeira subdivisão dentro das emissões, ou seja, as emissões diretas, estas que demonstram a informação sobre o tipo de informação e sobre a gestão de desempenho. O último fator é dividido em sistema métrico, uso de protocolos e tendências.

Nesta análise, são destacadas as dez empresas melhor colocadas dentro do fator emissões diretas nos três anos, considerando a média geral em percentual dos quatro fatores analisados que possuem dados ou seja, o tipo de informação, o sistema métrico, o uso de protocolos e as tendências. Diante disso, a partir do Quadro 3, apresenta-se o ranking das empresas brasileiras, a partir da frequência obtida pela divulgação dos fatores ambientais sobre as emissões diretas.

De acordo com os dados do Quadro 3, percebe-se que, no geral, das empresas do ranking, no ano de 2012, a frequência (percentual de evidenciação sobre emissões diretas por meio dos Relatórios de Sustentabilidade) foi melhor que nos demais anos, pois as cinco primeiras colocadas tiveram, em todos os fatores analisados, $100 \%$ de evidenciação; de modo que foi verificado o máximo de informações que buscava-se encontrar sobre cada um dos critérios nas empresas Klabin S/A, Santander, Suzano Papel, Tractebel e a empresa Vale. Além disso, verifica-se que, de ano em ano, esse percentual foi aumentando, visto que, em 2010, a primeira empresa colocada apresenta um percentual de $88 \%$ dos fatores evidenciados no geral sobre as emissões diretas. Em 2011, esse percentual aumentou para 94\%; e, em 2012, foi para 100\%.
Nota-se que a empresa Energias BR que, e 2011 assumiu a 1ª colocação no ranking, em 2012 decaiu para a 6 $6^{\text {a }}$ posição; portanto, no ano de 2012, a empresa passou a evidenciar, por meio de seu Relatório de Sustentabilidade, menos fatores no que diz respeito às emissões diretas. A empresa Klabin S/A que liderava o ranking em 2012, nos anos de 2010 e 2011 estava na $4^{\text {a }}$ e 2 $2^{\text {a }}$ colocação, respectivamente. Diante disso, percebe-se que esta empresa foi, em todos os anos, evidenciando mais os fatores sobre as emissões diretas. O contrário ocorreu com a empresa Petrobras que, em 2010, estava na $3^{\text {a }}$ colocação; em 2011, decaiu para a $4^{\mathrm{a}}$; e, em 2012, foi para a $7^{\mathrm{a}}$ colocação. Também verificou-se o mesmo na empresa BRF Foods S/A, que da 2a posição em 2010 caiu para 3a em 2011.

Percebe-se que várias empresas do ranking apresentam uma queda de posição de um ano para o outro, como é o caso da Braskem, da Duratex, da Ecorodovias e da P. Açúcar. O contrário pode ser notado nas empresas Bradesco, e, principalmente, Tractebel, visto que de $9^{\mathrm{a}}$ colocada no ranking em 2010 passou para $4^{\text {a }}$ posição em 2012. Por meio da Tabela 1 apresentam-se os fatores sobre emissões diretas que foram evidenciados pelas empresas analisadas em seus Relatórios de Sustentabilidade.

Para melhor entendimento da Tabela 1, necessita-se primeiramente explicitar sobre as escalas relacionadas aos níveis, que foram verificados de acordo com os aspectos analisados nos Relatórios de

Quadro 3 - Ranking das empresas brasileiras que mais evidenciaram sobre emissões diretas.

\begin{tabular}{|c|c|c|c|c|c|}
\hline \multicolumn{2}{|c|}{2010} & \multicolumn{2}{c|}{2011} & \multicolumn{2}{c|}{2012} \\
\hline Empresas & $\% *$ & Empresas & $\% *$ & Empresas & $\% *$ \\
\hline AMBEV & 88 & ENERGIAS BR & 94 & KLABIN S/A & 100 \\
\hline BRF FOODS & 88 & KLABIN S/A & 94 & SANTANDER & 100 \\
\hline PETROBRAS & 88 & BRF FOODS & 88 & SUZANO PAPEL & 100 \\
\hline KLABIN S/A & 85 & PETROBRAS & 88 & TRACTEBEL & 100 \\
\hline BRASKEM & 81 & P. AÇUCAR & 85 & VALE & 100 \\
\hline DURATEX & 81 & BRASKEM & 81 & ENERGIAS BR & 94 \\
\hline ECORODOVIAS & 81 & DURATEX & 81 & PETROBRAS & 88 \\
\hline LIGHT S/A & 81 & ELETROBRAS & 79 & P. AÇUCAR & 85 \\
\hline TRACTEBEL & 81 & BRADESCO & 75 & TIM PART S/A & 85 \\
\hline BRADESCO & 75 & ECORODOVIAS & 73 & BM\&FBOVESPA & 81 \\
\hline
\end{tabular}

*percentual de evidenciação sobre emissões diretas por meio dos Relatórios de Sustentabilidade.

Tabela 1 - Fatores sobre emissões diretas evidenciados das empresas.

\begin{tabular}{l|c|c|c|c}
\multirow{2}{*}{ Emissões diretas } & \multirow{2}{*}{$\begin{array}{c}\text { Tipo de } \\
\text { Informação }\end{array}$} & \multicolumn{3}{|c}{ Gestão de desempenho } \\
\cline { 3 - 5 } & Sistema & $\begin{array}{c}\text { Uso de } \\
\text { métrico }\end{array}$ & Tendências \\
\hline 2010 & $\mathrm{~N} 6$ & $\mathrm{~N} 1$ & $\mathrm{~N} 2$ & $\mathrm{~N} 1$ \\
\hline 2011 & $\mathrm{~N} 6$ & $\mathrm{~N} 1$ & $\mathrm{~N} 2$ & $\mathrm{~N} 1$ \\
\hline 2012 & $\mathrm{~N} 6$ & $\mathrm{~N} 4$ & $\mathrm{~N} 1$ & $\mathrm{~N} 1$ \\
\hline Escala dos níveis & $\mathrm{N} 1-\mathrm{N} 8$ & $\mathrm{~N} 1-\mathrm{N} 4$ & $\mathrm{~N} 1-\mathrm{N} 2$ & $\mathrm{~N} 1-\mathrm{N} 6$ \\
\hline
\end{tabular}


Sustentabilidade, conforme o Quadro 1, em cada uma das empresas da amostra e ano. Além disso, utilizou-se, para essa análise, o nível mais evidenciado dentro de cada fator.

Dessa forma, verifica-se na Tabela 1, no que tange que o fator tipo de informação, que, nos três anos analisados, este foi o mesmo nível 6 (N6), que representa que, no relatório da maioria das empresas sobre as emissões diretas, foram evidenciadas informações descritivas e quantitativas. Os demais níveis representam: N1 - nenhuma informação; N2 - informação descritiva; N3 - informação monetária; N4 informação quantitativa; N5 - informação descritiva e monetária; N7 informação quantitativa e monetária; e, por fim, N8 - que apresenta os três tipos de informação (descritiva, quantitativa e monetária).

Em relação à gestão de desempenho, no qual enquadra-se o sistema métrico, este que aborda se a empresa utiliza um Sistema Métrico Internal (SMI) e/ou Padrão de Conversão (PC) para os dados. Nota-se que, nos anos de 2010 e 2011, a maioria das empresas não evidenciou informações, ou seja, apresentou o nível N1. Já em 2012 a maioria das empresas analisadas utilizou-se dos dois sistemas em seu Relatório de Sustentabilidade, isto é, nível N4 - que significa a utilização dos sistemas SMI e PC.

O uso de protocolos nos anos de 2010 e 2011 foi evidenciado pela maioria das empresas e o contrário ocorreu em 2012, uma vez que a maioria das empresas analisadas não utilizou-se destes protocolos para divulgar as informações no seu relatório. No que diz respeito às tendências analisadas nos relatórios, que seria a periodicidade informada dos programas, verifica-se que, dentre as empresas analisadas, a maioria não evidencia a periodicidade nos três anos analisados - ou seja, em todos os anos o nível foi N1.

\section{Emissões indiretas}

Em relação às emissões indiretas que foram verificadas nos Relatórios de Sustentabilidade das empresas analisadas, observa-se que estão divididas em tipo de informação e gestão de desempenho (como nas emissões diretas), sendo que o último fator divide-se em sistema métrico, uso de protocolos e tendências, conforme apresenta-se na Figura 2. Nesta análise, serão destacadas por meio de figuras de cada ano analisado as cinco empresas brasileiras melhor colocadas no ranking geral - aquelas que mais evidenciam sobre as emissões. Utilizou-se o ranking geral para selecionar as cinco primeiras empresas brasileiras e seus fatores sobre as emissões indiretas, sendo analisado o nível evidenciado no tipo de informação no sistema métrico, no uso de protocolos e nas tendências destas empresas nos três anos analisados. Por meio da Figura 3 pode-se visualizar a divisão das emissões indiretas e evidenciação dos fatores destas cinco primeiras empresas posicionadas no ranking em 2010.

$\mathrm{Na}$ Figura 2, nota-se que das empresas do ranking dos três anos analisados, no que se refere ao tipo de informação sobre as emissões diretas que somente as empresas Braskem e a Suzano Papel apresentaram dados diferentes das demais empresas que apresentaram informações descritivas e quantitativas (DQ). Dessa forma, a Braskem apresentou informações quantitativas (Q) e a empresa Suzano Papel, descritivas, quantitativas e monetárias (DQM) em seus relatórios.

Já sobre a gestão do desempenho que abrange o sistema métrico, percebe-se que somente em 2012 todas as empresas analisadas utilizaram

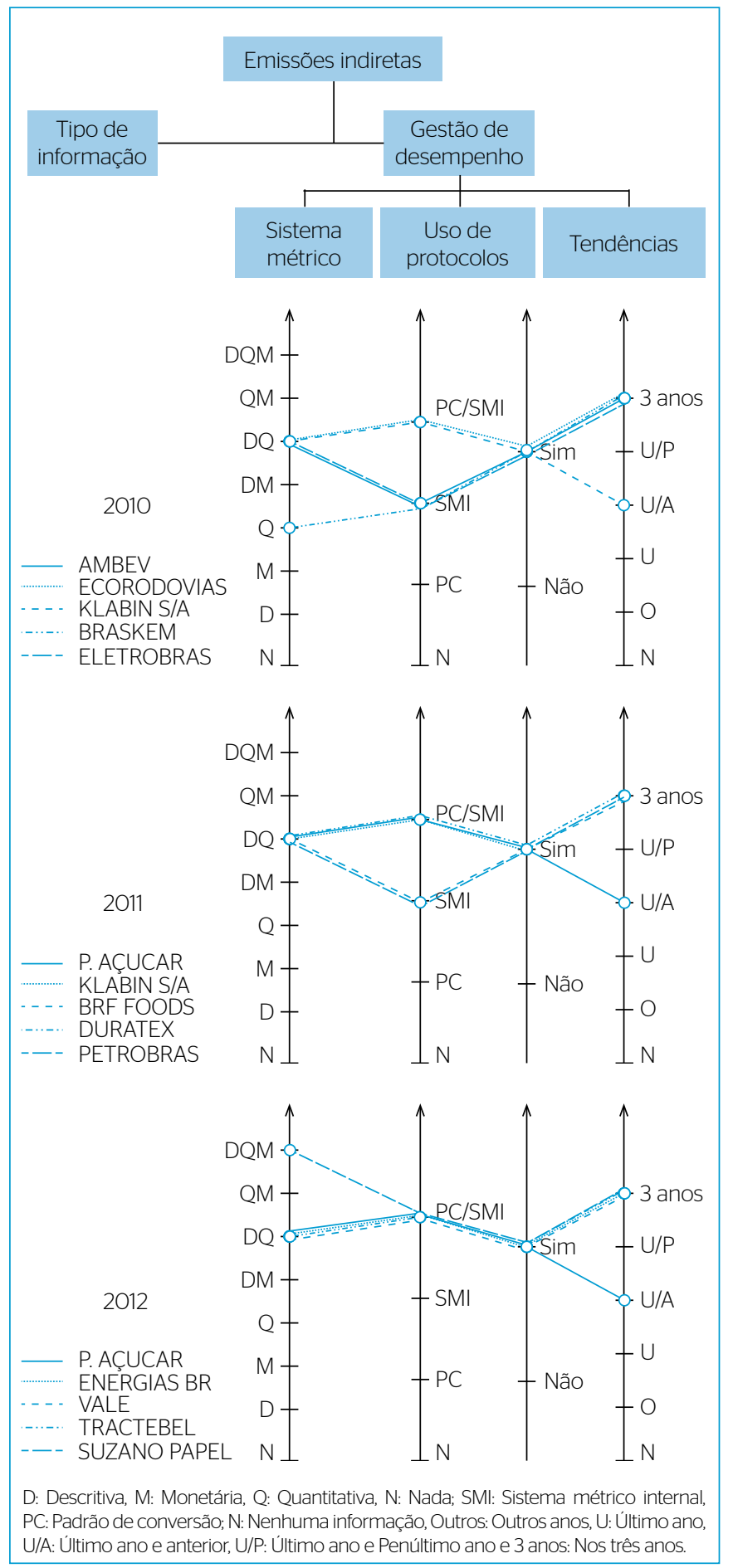

Figura 2 - Emissões indiretas 2010, 2011 e 2012. 
o PC e SMI, sendo que nos anos de 2010 e 2011, a utilização foi dividida tanto em SMI quanto em PC e SMI. Em relação aos protocolos, em todos os anos analisados, as empresas do ranking evidenciaram que utilizam estes para as informações prestadas. No que se refere às tendências, a periodicidade informada dos programas é, na maioria dos casos analisados, de três anos. Ressalta-se que em 2010 a empresa Klabin S/A foi aquela que apresentou periodicidade informada dos programas do último ano e anterior (U/A). Já em 2011 e 2012, foi a empresa P. Açúcar que evidenciou essa mesma periodicidade informada dos programas que a Klabin S/A.

\section{Emissões de substâncias destruidoras da Camada de Ozônio}

Em relação às emissões de substâncias destruidoras da Camada de Ozônio, identificou-se que, no ano de 2010, perante a amostra de 31 empresas, 22 destas divulgaram informações referente a esse tipo de evidenciação ambiental e nove empresas apenas não divulgaram nenhum tipo de informação deste tipo. No que tange ao ano de 2011, das 33 empresas analisadas, 26 evidenciaram informações sobre as emissões de substâncias destruidoras da Camada de Ozônio e sete empresas não apresentaram em seus Relatórios de Sustentabilidade dados relativos a essa informação. Quanto ao ano de 2012, 36 empresas divulgaram informações relacionadas a este item e sete empresas não prestaram essa informação, em relação a um total de 43 empresas da amostra. Este resultado evidencia que as empresas analisadas, na sua grande maioria, preocupam-se em demonstrar à sociedade as substâncias que a empresa emite e que provocam a destruição da Camada de Ozônio, uma vez sendo identificado esse fator nos Relatórios de Sustentabilidade.

\section{Emissões de Nox, Sox e outras substâncias significativas}

Outro fator que foi analisado nos Relatórios de Sustentabilidade é referente às emissões de Nox, Sox e outras substâncias significativas, sendo que se verificou que, nos anos de 2010 e 2011, basicamente as empresas da amostra evidenciaram, na mesma proporção, informações relativas a essas substâncias: 16 empresas em 2010 e 18 empresas em 2011. Já em relação às empresas desses anos que não evidenciaram em seus relatórios informações desse tipo, apresentou-se igual o número de empresas: 15 empresas de cada ano da amostra analisada.

O ano de 2012 foi o ano que mais apresentou empresas que não evidenciam informações referentes às emissões de Nox, Sox e outras substâncias significativas, pois, dentre a amostra de 43 empresas, 25 destas não apresentaram informações em seus Relatórios de Sustentabilidade. Este fato demonstra que as empresas analisadas, de 2011 a 2012, deixaram de apresentar uma preocupação maior para a divulgação dessas informações, visto que mais empresas não evidenciaram informações desse fator no Relatório de Sustentabilidade, comparado aos demais anos que foram analisados neste estudo.

\section{Redução de emissões}

Para realizar esta análise, utilizou-se as dez empresas brasileiras que ficaram melhor colocadas no fator de redução de emissões, ou seja, as empresas que mais evidenciaram em seus Relatórios de Sustentabilidade os aspectos demonstrados na Figura 6, a partir da média geral, que é apresentada em percentual, dos três fatores analisados e que possuem os devidos dados, isto é, tipo de informação, ocorrência e tendências. Frente ao exposto, no Quadro 4, demonstra-se, por meio de um ranking, as empresas brasileiras e sua respectiva frequência que foi alcançada com a divulgação dos fatores ambientais relacionados a redução de emissões.

Conforme os dados do Quadro 4, nota-se que, no geral, as empresas colocadas no ranking referente o ano de 2012, apresentaram a melhor frequência, isto é, o percentual de evidenciação relacionado à redução de emissões divulgada nos Relatórios de Sustentabilidade foi melhor, visto que nos demais anos analisados a frequência apresentou-se menor. Porém, nos anos de 2010, 2011 e 2012, a empresa Ambev e P. Açúcar apresentaram a mesma frequência, que seja, evidenciaram o mesmo percentual de informações nos Relatórios de Sustentabilidade sobre os fatores analisados de redução de emissões. Para tanto, verifica-se que a divulgação de informações nos Relatórios de Sustentabilidade sobre a redução de emissões foi aumentando de ano a ano.

Demonstra-se por meio dos dados apresentados no Quadro 4 que a empresa P. Açucar, no ano de 2010 apresentava-se em $4^{a}$ posição no ranking, sendo que nos demais anos, passou a evidenciar por meio de seu Relatório de Sustentabilidade, mais fatores relacionados a redução de emissões, ficando dessa forma em $1^{\circ}$ lugar no ranking nos anos de 2011 e 2012. A empresa Braskem, nos anos de 2010 e 2011, constava na $3^{\text {a }}$ colocação no ranking, o que mostra

Quadro 4 - Ranking das empresas brasileiras que mais evidenciaram sobre redução de emissões.

\begin{tabular}{|c|c|c|c|c|c|}
\hline \multicolumn{2}{|c|}{2010} & \multicolumn{2}{c|}{2011} & \multicolumn{2}{c|}{2012} \\
\hline Empresas & $\%$ & Empresas & $\%$ & Empresas & $\%$ \\
\hline AMBEV & 69 & P. AÇUCAR & 69 & P. AÇUCAR & 69 \\
\hline BRF FOODS & 63 & TRACTEBEL & 54 & ELETROBRAS & 60 \\
\hline BRASKEM & 50 & BRASKEM & 50 & BM\&FBOVESPA & 56 \\
\hline P. AÇUCAR & 48 & BRF FOODS & 44 & LIGHT S/A & 54 \\
\hline KLABIN S/A & 42 & ELETROBRAS & 42 & BRF FOODS & 50 \\
\hline ECORODOVIAS & 42 & KLABIN S/A & 42 & ECORODOVIAS & 50 \\
\hline DURATEX & 29 & BRADESCO & 38 & ENERGIAS BR & 48 \\
\hline EVEN & 29 & BANRISUL & 35 & EVEN & 48 \\
\hline PETROBRAS & 29 & EVEN & 35 & BRASKEM & 42 \\
\hline TRACTEBEL & 29 & MULTIPLAN & 35 & OI & 42 \\
\hline
\end{tabular}


que esta empresa nesse período, evidenciou em seu Relatório de Sustentabilidade o mesmo percentual de informações sobre a redução de emissões, contudo, isto não ocorreu no ano de 2012, quando a empresa decaiu para a $9^{a}$ posição, o que demonstra que passou a evidenciar menos informações referentes à redução de emissões em seu Relatório de Sustentabilidade.

Outra empresa que apresentou uma queda na evidenciação ambiental em seu Relatório de Sustentabilidade foi a BRF Foods. Ela evidenciou menos informações sobre o fator de redução de emissões, pois no ano de 2010 estava na $2^{\text {a }}$ colocação no ranking, passando a ocupar a $4^{\circ}$ e $5^{a}$ posição em 2011 e 2012, respectivamente. O contrário ocorreu para a empresa Tractebel, que estava na última colocação do ranking no ano de 2010, passando em 2011 para a $2^{\mathrm{a}}$ e no ano seguinte não esteve entre as 10 empresas que mais evidenciaram informações em seus Relatórios de Sustentabilidade referente à redução de emissões.

Destaca-se, também, a empresa Even, que, no ano de 2010, constava na $8^{\text {a }}$ posição do ranking, decaindo para a $9^{\mathrm{a}}$ posição no ano de 2011 e reagindo no ano de 2012, passando novamente para a $8^{\text {a }}$ posição, ou seja, no ano de 2012 voltou a evidenciar mais informações sobre a redução de emissões no Relatório de Sustentabilidade. No entanto, percebe-se que outras empresas tiveram uma queda de posição no ranking, como é o caso da empresa Klabin, nos anos de 2010 e 2011, sendo que em 2012, não apresentou significativa para a análise realizada das empresas que mais evidenciaram informações sobre emissões da amostra.

Em relação aos fatores relativos à redução de emissões que foram divulgados pelas empresas brasileiras em seus Relatórios de Sustentabilidade, verificou-se que, nos três anos analisados, a maioria das empresas não evidenciou informações. Diante disso, o ano que a maioria das empresas analisadas apresentou dados sobre redução de emissões foi em 2012, no fator tipo de informação, no qual evidenciaram subsídios descritivas e quantitativas.

\section{CONCLUSÃO}

Esta pesquisa objetivou analisar a evidenciação ambiental sobre as emissões das empresas brasileiras. Para tanto, realizou-se uma pesquisa descritiva, documental e qualitativa. A população do estudo é composta por 100 empresas brasileiras listadas no IBrX100 da BM\&FBovespa e a amostra constitui-se de 31 empresas em 2010, 33 em 2011 e 43 em 2012, tendo como critério as que divulgaram dados sobre emissões em seus Relatórios de Sustentabilidade. O período de análise compreendeu três anos, sendo os de 2010, 2011 e 2012. A análise foi realizada por meio de um ranking elaborado com base nos Relatórios de Sustentabilidade sobre emissões ambientais.
Os resultados demonstraram que, em relação às emissões ambientais, as empresas que mais se destacaram nos rankings de evidenciação são as empresas P. Açúcar e Klabin S/A. Além disso, a maioria das empresas apresentou informações descritivas e quantitativas nos três anos analisados. Em relação à emissão de substâncias destruidoras da Camada de Ozônio e as emissões de Nox, Sox e outras substâncias significativas, a maioria das empresas evidenciam dados. Sobre a redução de emissões a maioria das empresas não apresentou documentos, ou seja, iniciativas de redução de emissões e a periodicidade dos programas.

Os estudos de Borges, Rosa e Ensslin (2010) e de Oliveira, Machado e Beuren (2012), mesmo que apresentando empresas diferentes que lideraram seus rankings, corroboram com os achados deste estudo, visto que os rankings podem alterar as empresas analisadas de um período para outro. Os resultados encontrados para as emissões diferem-se dos achados de Nossa (2002), pois a maioria das informações ambientais foi evidenciada de forma descritiva.

No que se refere às empresas brasileiras, tem-se um grande número que não apresenta disponível seus Relatórios de Sustentabilidade, sendo que outras o divulgam. Porém, não evidenciam informações ambientais. O estudo de Ben (2005) corrobora com este achado, visto que os resultados demonstraram também a ausência de divulgação de informações ambientais. Isso se confirma, quando verifica-se, por exemplo, a redução das emissões, pois, neste estudo, a maioria das empresas não divulgou informações a respeito deste aspecto. Além disso, o estudo de Calixto (2007) também corrobora com os achados, pois verificou diferenças no nível de evidenciação, em que algumas empresas divulgaram mais informações do que outras. Na presente pesquisa, este fato pode ser verificado no que diz respeito às emissões indiretas, devido ao fato das empresas que lideraram o ranking apresentarem diferentes níveis sobre o tipo de informação, sistemas métrico, uso de protocolos e tendências.

O estudo de Silva et al. (2013) identificou que as empresas analisadas possuem a tendência de divulgar informações ambientais de forma voluntária. Exemplo disso é o fato de as empresas darem ênfase a um projeto ambiental que estão desenvolvendo, sem trazer no seu relatório a redução de fato dos impactos ambientais que a empresa causa ao meio ambiente.

As limitações do estudo referem-se ao acesso dos Relatórios de Sustentabilidade e ao fato das empresas, muitas vezes, mesmo tendo o relatório, não evidenciarem dados - neste caso, sobre as emissões ambientais. Além disso, o resultado obtido neste estudo não pode ser generalizado, pois foram analisadas apenas as empresas que apresentaram dados no período descrito. Como sugestões de pesquisas futuras, recomenda-se a análise da evidenciação ambiental sobre emissões de todas as empresas brasileiras, verificar outros aspectos ou países, a fim de comparar os resultados com os obtidos neste estudo. 


\section{REFERÊNCIAS}

BEN, F. (2005) Evidenciação de informações ambientais pelas empresas gaúchas. Revista Universo Contábil, v. 1, n. 3, p. 63-80

BORGES, A.P.; ROSA, F.S.; ENSSLIN, S.R. (2010) Evidenciação voluntária das práticas ambientais: um estudo nas grandes empresas brasileiras de papel e celulose. Produção On Line, v. 20, n. 3, p. 404-417

CALIXTO, L. (2007) Uma análise da evidenciação ambiental de companhias brasileiras-de 1997 a 2005. UnB Contábil, v. 10, n. 1, p. 9-37

CARNEIRO, J.E.; LUCA, M.M.M. de; OLIVEIRA, M.C. (2008) Análise das Informações Ambientais Evidenciadas nas Demonstrações Financeiras das Empresas Petroquímicas Brasileiras listadas na Bovespa. Revista Contabilidade Vista e Revista, v. 19, n. 3, p. 39-67.

DAUB, C.-H. (2007) Assessing the quality of sustainability reporting: an alternative methodological approach. Journal of Cleaner Production, v. 15, n. 1, p. 75-85

ERLANDSSON, J. \& TILLMAN, A. (2009) Analysing influencing factors of corporate environmental information collection, management and communication. Journal of Cleaner Production, v. 17, n. 9, p. 800-810

FARIAS, K.T.R. (2008) A relação entre divulgação ambiental, desempenho ambiental e desempenho econômico nas empresas brasileiras de capital aberto: uma pesquisa utilizando equações simultâneas. 189 f. Dissertação (Mestrado em Controladoria e Contabilidade) - Faculdade de Economia, Administração e Contabilidade de Ribeirão Preto da Universidade de São Paulo, São Paulo.

FARIAS, L.G.Q. \& ANDRADE, J.C.S. (2013) Evidenciação ambiental para o enfrentamento das mudanças climáticas: as respostas de empresas brasileiras do Carbon Disclosure Project. Reuna, v. 18, n. 3 , p. $111-126$

FERREIRA, A.C.S. (2011) Contabilidade ambiental: uma informação para o desenvolvimento sustentável. 3. ed. São Paulo: Atlas

JENKINS, H. \& YAKOVLEVA, N. (2006) Corporate social responsibility in the mining industry: Exploring trends in social and environmental disclosure. Journal of Cleaner Production, v. 14, n. 3 , p. 271-284
LIU, X. \& ANBUMOZHI, V. (2009) Determinant factors of corporate environmental information disclosure: an empirical study of Chinese listed companies. Journal of Cleaner Production, v. 17, n. 6, p. 593-600

LUNGU, C.I.; CARAIANI, C.; DASCĂLU, C. (2007) New Perspectives on Corporate Reporting: Social-Economic and Environmental Information. Theoretical and Applied Economics, v. 11, n. 11, p. 37-42

NOSSA, V. (2002) Disclosure ambiental: uma análise do conteúdo dos relatórios ambientais de empresas do setor de papel e celulose em nível internacional. 246 f. Tese (Doutorado em Controladoria e Contabilidade) - Faculdade de Economia, Administração e Contabilidade da Universidade de São Paulo, São Paulo

OLIVEIRA, A.F.; MACHADO, D.G.; BEUREN, I.M. (2012) Evidenciação ambiental de empresas de setores potencialmente poluidores listadas no Índice de Sustentabilidade Empresarial (ISE). Revista de Gestão Social e Ambiental, v. 6, n. 1, p. 20-37.

RIBEIRO, M.S. (2006) Contabilidade ambiental. São Paulo: Saraiva.

ROSA, F.S.; ENSSLIN, S.R.; ENSSLIN, L.; LUNKES, R.J. (2011) Gestão da evidenciação ambiental: um estudo sobre as potencialidades e oportunidades do tema. Revista Engenharia Sanitária Ambiental, v. 16, n. 1, p. 157-166.

SILVA, T.L.; VICENTE, E.F.R.; PFITSCHER, E.D.; ROSA, F.S. (2013) Environmental disclosure-informações sobre resíduos sólidos divulgadas pelas empresas potencialmente poluídoras listadas na BM\&FBOVESPA. Revista Ambiente Contábil, v. 5, n. 2, p. 229-249

SKOULOUDIS, A.; EVANGELINOS, K:; KOURMOUSIS, F. (2010) Assessing non-financial reports according to the Global Reporting Initiative guidelines: evidence from Greece. Journal of Cleaner Production, v. 18, n. 5, p. 426-438

TINOCO, J.E.P. \& KRAEMER, M.E.P. (2011) Contabilidade e gestão ambiental. 3. ed. atual. de acordo com as Leis n. 11.638/2007, e 11.941/2009. São Paulo: Atlas.

TRIERWEILLER, A.C.; PEIXE, B.C.S.; TEZZA, R.; BORNIA, A.C.; CAMPOS, L.M.S. (2012) Measuring environmental management disclosure in industries in Brazil with item response theory. Journal of Cleaner Production, v. 47, p. 298-305 